\title{
Synthesis and Growth Kinetics of Monodispersive Indium Hydrate
} Particles

\author{
Sung-En Lin and Wen-Cheng J. Wei ${ }^{\dagger}$ \\ Institute of Materials Science and Engineering, National Taiwan University, Taipei, Taiwan 106, Republic of China
}

\begin{abstract}
Nano- or submicron $\operatorname{In}(\mathrm{OH})_{3}$ and $\mathrm{In}_{2} \mathrm{O}_{3}$ particles of different morphologies were synthesized from a nitrate solution by a homogeneous precipitation process. By using X-ray diffractometer, thermogravimetric analysis, transmission and scanning electron microscopes, and inductively coupled plasma-optical emission spectrometry, the properties of particle growth were analyzed. The results indicated that the kinetics of the hydrolysis reaction of $\mathrm{In}^{3+}$ was a zero-order reaction with an activation energy of $128 \mathrm{~kJ} / \mathrm{mol}$, which implied that the reaction was controlled by the decomposition kinetic of urea additive. The growth anisotropic of particles, $\mathrm{pH}$ value of reaction solutions, residual $\mathrm{In}^{3+}$ concentration relative to aging time with different temperatures and starting concentrations were reported in this study. Calcination of the hydrate to form $\operatorname{In}_{2} \mathrm{O}_{3}$ particles between $300^{\circ}$ and $900^{\circ} \mathrm{C}$ did not greatly change the morphologies of the particles.
\end{abstract}

\section{Introduction}

TNDIUM OXIDE $\left(\operatorname{In}_{2} \mathrm{O}_{3}\right)$, an $n$-type semiconductor with a wide bandgap of about $3.6 \mathrm{eV}$, has been used as a luminescent material, ${ }^{1,2}$ microelectronic material for the devices of solar cells, and flat panel displays. The oxide with an appropriate dopant can also be used as architectural glasses, ${ }^{3}$ gas sensors, ${ }^{4}$ photocatalysts ${ }^{5}$ for the oxidation of organic and inorganic compounds, or an electrically conductive pigment. $^{6}$

Many powder synthesis methods using urea decomposition have been reported. Basically, the chemical reaction is based on controling the acidity of a solution and can be described as below.

$$
\left(\mathrm{NH}_{2}\right)_{2} \mathrm{CO}+3 \mathrm{H}_{2} \mathrm{O} \rightarrow \mathrm{CO}_{2}+2 \mathrm{NH}_{4}^{+}+2 \mathrm{OH}^{-}
$$

Previous studies ${ }^{7-14}$ have demonstrated that urea could play an essential role in the formation of uniform particles. Boschini et al. ${ }^{7}$ prepared nano-sized barium zirconate powder by thermal decomposition of urea in an aqueous solution containing $\mathrm{Ba}^{2+}$ and $\mathrm{Zr}^{4+}$. Another case was reported by Wang et al. ${ }^{8}$ on uniform needle-like aragonite particles obtained by aging the solutions of Ca salts in the presence of urea at $90^{\circ} \mathrm{C}$. Song and Kang ${ }^{9}$ demonstrated that high-surface area and monodispersive tin oxide powder has been synthesized with the help of urea decomposition. They found that the formation of different polymorphs of ceramic particles was affected greatly by the concentration of reactants, as well as by the mixing procedure. Similar homogeneous precipitation methods have also been used to synthesize $\mathrm{ZnS},{ }^{10} \mathrm{Fe}_{2}\left(\mathrm{SO}_{4}\right)_{3}{ }_{11}^{11} \mathrm{Cd}_{2} \mathrm{O}_{3}$ - and $\mathrm{Sm}_{2} \mathrm{O}_{3}$-doped $\mathrm{CeO}_{2}$ solid electrolyte powder, ${ }^{12,13}$ and $\mathrm{YBO}_{3}: \mathrm{Eu}^{3+}$ luminescent material. ${ }^{14}$ However, only a few articles ${ }^{15,16}$ have focused on the prepara-

R. French-contributing editor tion of $\operatorname{In}_{2} \mathrm{O}_{3}$ or $\operatorname{In}(\mathrm{OH})_{3}$ powders by using the homogeneous precipitation method.

Monodispersive and uniform particles have many potential and important applications, e.g., for the manufacture of photonic bandgap crystals, catalysts, or as model materials for fundamental studies in colloidal and surface sciences. In this paper, we report our observation on the precipitation behavior of $\operatorname{In}(\mathrm{OH})_{3}$ with different aging periods and urea additions. The kinetics of the hydrolysis reaction of $\mathrm{In}^{3+}$ at the temperatures $65^{\circ}-85^{\circ} \mathrm{C}$ is quantified and investigated in this work.

\section{Experimental Procedure}

\section{(1) Materials and Sample Preparation}

Two chemicals, indium nitrate $(99.9 \%$ pure, Titanex Corp. Mönchaltorf, Switzerland), and urea (99.5\% pure, Acros, Geel, Belgium) were used for the preparation of $\operatorname{In}(\mathrm{OH})_{3}$ and $\mathrm{In}_{2} \mathrm{O}_{3}$ particles. In this study, the source of $\mathrm{OH}^{-}$came from the thermo-decomposition of urea in an aqueous solution.

The experiments used the solution concentration of $\operatorname{In}\left(\mathrm{NO}_{3}\right)_{3}$ at $0.02 \mathrm{~mol} / \mathrm{L}$, and the urea concentration adjusted from 0 to 3 $\mathrm{mol} / \mathrm{L}$. The urea was dissolved in the de-ionized water, and then added in the diluted $\mathrm{In}\left(\mathrm{NO}_{3}\right)_{3}$ solution. The mixture was sealed in a glass jug and aged at either $85^{\circ}$ or $65^{\circ} \pm 0.2^{\circ} \mathrm{C}$, which was named either "process A" or "process B." The aging of the solutions lasted normally up to $17 \mathrm{~h}$.

\section{(2) Characterization}

White precipitates were observed in the reaction mixture in less than $30 \mathrm{~min}$. The precipitation reaction could be terminated by instant dilution of the suspension in de-ionized water on cooling at room temperature. To separate the particles, dispersions were centrifuged for $40 \mathrm{~min}$ at $6000 \mathrm{rpm}$ and the supernatant solution was discarded. This centrifugation process was repeated at least three times. For each cycle, the centrifuged particles were re-dispersed in the de-ionized water. In the first cycle, the supernatant solution was collected and diluted for inductively coupled plasma (ICP)-optical emission spectrometry (OES) measurement.

Dry powder was collected from centrifugation of suspension and washed by de-ionized water at least three times and then dried at $105^{\circ} \mathrm{C}$ for more than $1 \mathrm{~h}$. About $10 \mathrm{mg}$ of the powder sample was placed in a Pt crucible and tested in a thermogravimetric analysis (TGA) system (Thermal Gravity Analyst 2000, Dupont Co., Wilmington, DE). The particle size and morphology were examined by scanning and transmission electron microscopes (Field Emission SEM, LEO 1530, Cambridge, U.K.; TEM 100 CXII (JEOL Co., Tokyo, Japan). The crystalline phase was examined by X-Ray diffractometry (XRD, Philips PW1710, Philips Co., Eindhoven, the Netherlands). The particle size and the aspect ratio were statistically measured from the SEM micrographs based on at least 50 particles.

\section{Results}

(1) Properties of Precipitates Prepared at $85^{\circ} \mathrm{C}$

The monodispersed nature and oval shape of the precipitates can be observed in Fig. 1. For process A, the size distribution is
Manuscript No. 20343. Received March 24, 2005; approved September 15, 2005. contract NSC 93-2120-M-002-011.

${ }^{\dagger}$ Author to whom correspondence should be addressed. e-mail: wjwei@ntu.edu.tw 

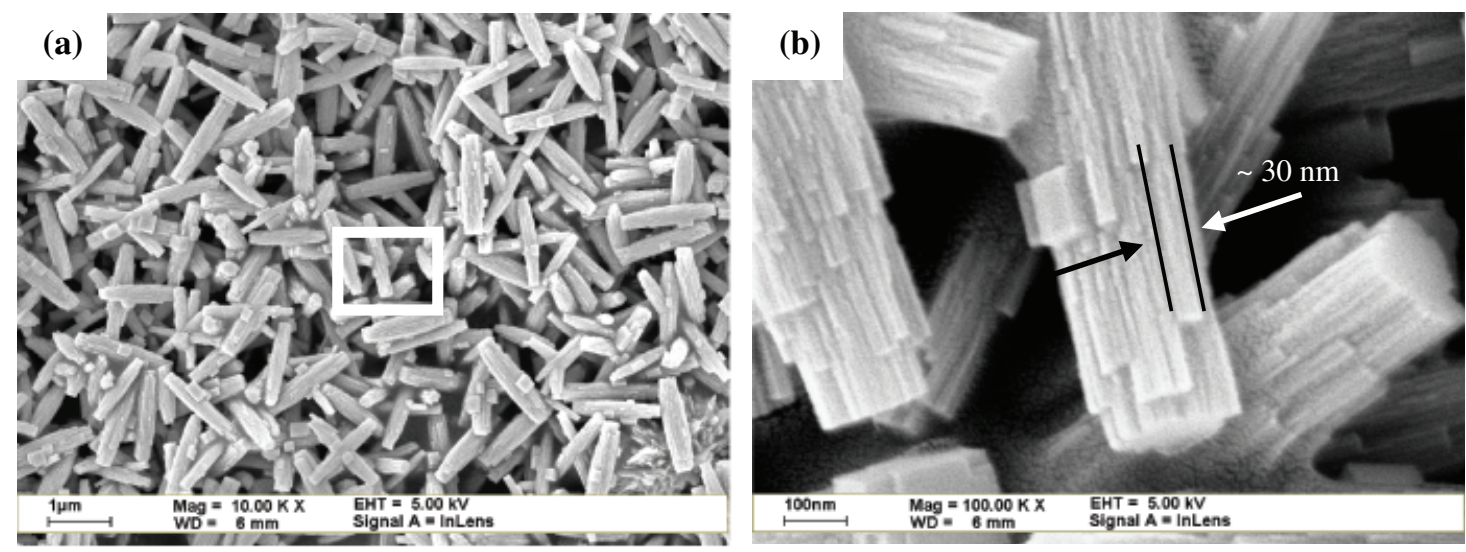

(c)

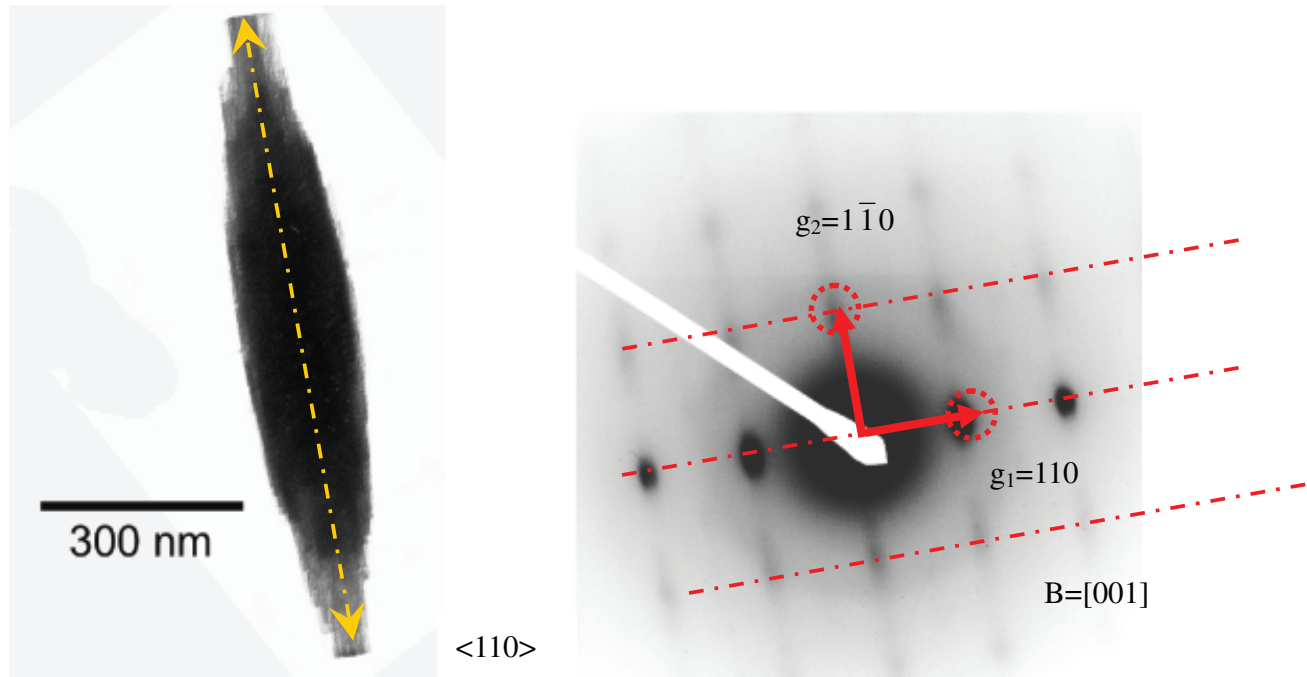

Fig. 1. Scanning electron microscope micrographs of sample A-2 with $0.5 \mathrm{~mol} / \mathrm{L}$ of urea addition aged for (a) $6 \mathrm{~h}$ and (b) one precipitate at a higher magnification, and (c) transmission electron microscope BF image and diffraction pattern (DP) of sample A-2. The DP shows that the oval-shaped particle has an $\mathrm{InO}(\mathrm{OH})$ phase with an orthorhombic structure, and the zone axis is [001].

narrow. Detailed surface morphology can be observed in the magnified image of Fig. 1(b). The particles seemed to be assembled from thin rods having diameters of about $30 \mathrm{~nm}$. Similar morphologies could be found for the other cases of process A. A difference in particle sizes, but similarity in oval shape and thin rod assembly, are the characteristics of the precipitates. The TEM BF image and the diffraction pattern (DP) of sample A-2 are shown in Fig. 1(c), which shows a single crystalline character. The nano-rods of the oval particle showed a similar crystalline orientation. The longitudinal direction of the particle was $\langle 110\rangle$ of the $\mathrm{InO}(\mathrm{OH})$ phase. However, the pattern became diffuse when the sample was exposed to a $100 \mathrm{keV}$ electron beam just for a few minutes.

The statistical results (measured from SEM micrographs) of particle size (length and width) as a function of aging periods are shown in Fig. 2. In all cases, the particle sizes almost stopped growing, when aged for $2 \mathrm{~h}$. The $\mathrm{pH}$ value increased with increasing urea addition. In the case of $1.0 \mathrm{~mol} / \mathrm{L}$ of urea addition, the precipitate grew to the largest particle size, both in terms of length and width. The particle size increased with increasing urea addition as the concentration of urea was $\leq 1.0 \mathrm{~mol} / \mathrm{L}$, and reached the largest value of about $1300 \mathrm{~nm}$ in length, and 300 $\mathrm{nm}$ in width, but decreased when more urea was added. The possible reasons for this will be discussed later.

The $\mathrm{pH}$ values decreased with the aging period in the case of no urea because of the hydrolysis process of the indium ion in solution. The $\mathrm{OH}^{-}$ion in solution participated in the hydrolysis reaction, and then the concentration of $\mathrm{OH}^{-}$ion in solution decreased with aging. In the other four cases (Fig. 2), the $\mathrm{pH}$ value first remained strong acidic, but increased dramatically on aging for a period of time. The more the urea added, the faster the $\mathrm{pH}$ increased. In order to interpret the phenomena, the ICPOES test of In species in solution was performed to examine the change of the In concentration in solution during the reaction.

The ICP-OES results of the residual concentration of In species in the reaction solution plotted against the aging period are

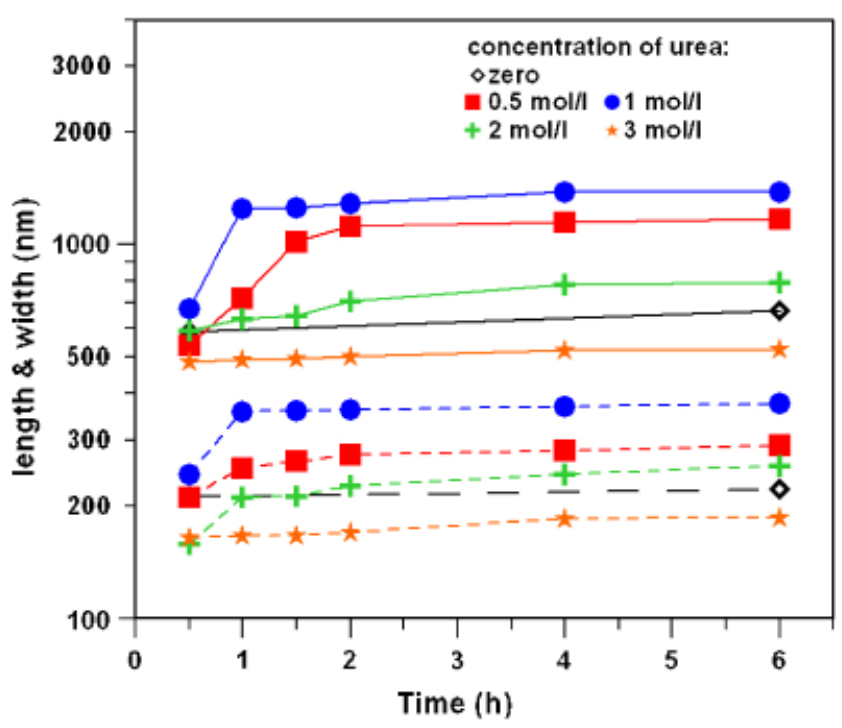

Fig. 2. Particle size (length, width) of process A with the addition of different urea concentrations plotted against the aging period. 

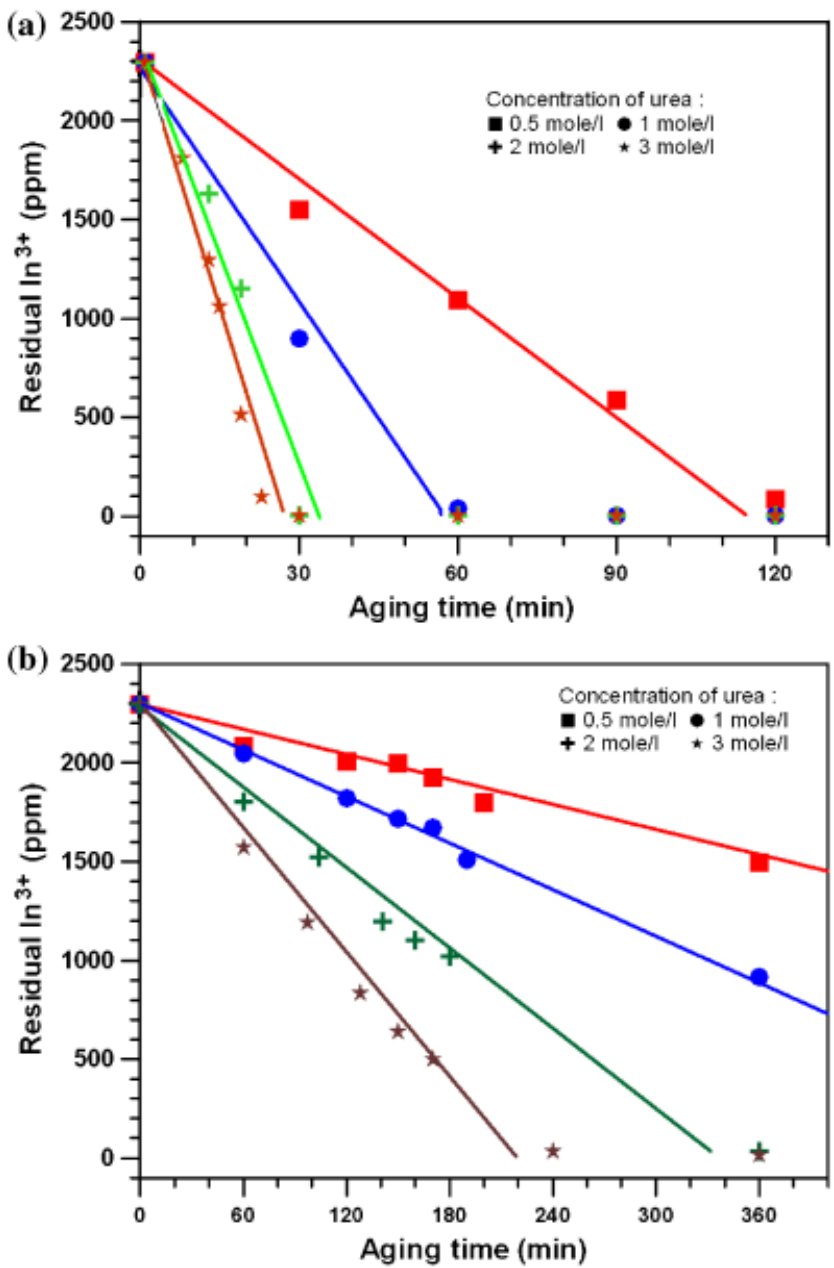

Fig. 3. Residual concentration of In ions in the solutions of (a) process $\mathrm{A}$, aged at $85^{\circ} \mathrm{C}$ and (b) process $\mathrm{B}$, aged at $65^{\circ} \mathrm{C}$, plotted against the aging time.

shown in Fig. 3. For process A, when $0.5 \mathrm{~mol} / \mathrm{L}$ of urea was added the residual In ion was almost used up on aging for longer than $3 \mathrm{~h}$. Similar situations were observed for other cases. In ions reduced to a $3 \mathrm{ppm}$ level on aging after 90, 30, and $25 \mathrm{~min}$ when 1,2 , and $3 \mathrm{~mol} / \mathrm{L}$ of urea was added, respectively, as shown in Fig. 3(a). The $\mathrm{pH}$ value increased dramatically as the In ions completely hydrolyzed.

The TEM micrographs of sample A-2 that was aged for $6 \mathrm{~h}$ are shown in Fig. 1(c). The diffraction pattern of the ovalshaped particle revealed a polycrystalline pattern with $g_{1}=110$ and $g_{2}=110$ faces of the $\mathrm{InO}(\mathrm{OH})$ crystal. The longitudinal direction is $\langle 110\rangle$, and further study of the XRD and the crystalline index will be discussed later. This is the reason why the precipitates grew to rod like or oval shape. A different result can be found in the research reported by Avivi et al. ${ }^{15}$ who reported on the nano-sized needle-shaped $\operatorname{In}(\mathrm{OH})_{3}$ particles prepared via the sonication of an aqueous solution of $\mathrm{InCl}_{3}$ at room temperature and at $0^{\circ} \mathrm{C}$. The TEM micrographs in their paper revealed bundles of rod-like structures, and were indexed as one $\operatorname{In}(\mathrm{OH})_{3}$ phase and one unknown phase by XRD. However, the unknown phase can be indexed as an $\operatorname{InO}(\mathrm{OH})$. They did not explain why the precipitates showed one type of precipitate morphology, but two crystalline phases.

\section{(2) Properties of Precipitates Prepared at $65^{\circ} \mathrm{C}$}

The average particle size of the In precipitate reported in this section was measured by Zetasizer (3000 HSA, Malvern Instruments, Malvern, U.K.). The average particle size plotted against aging time with different urea concentrations is shown in Fig. 4.

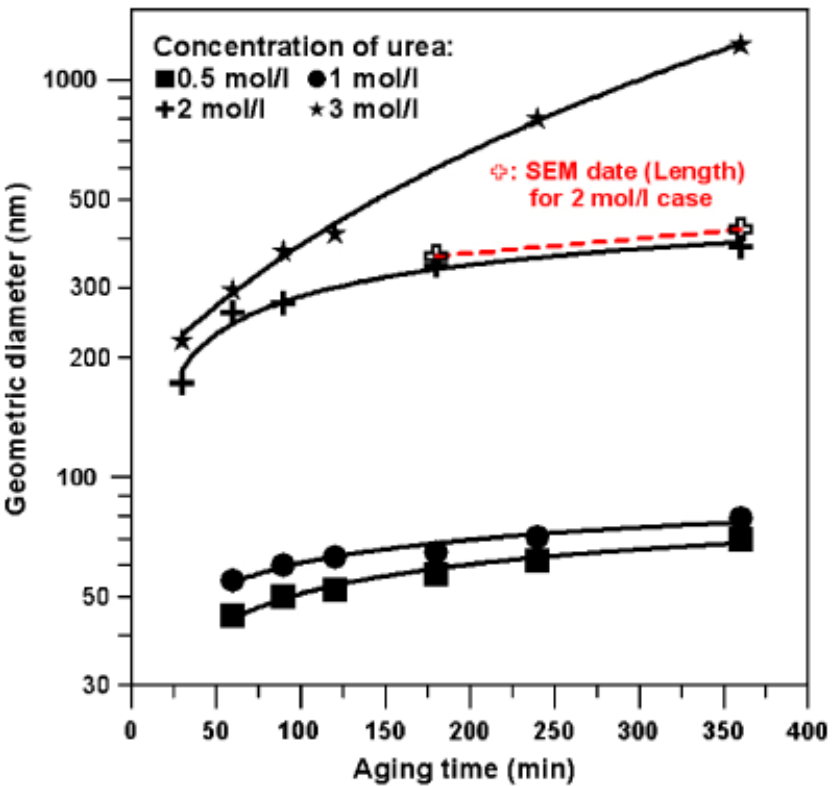

Fig. 4. Geometric diameter of process B with different urea concentrations plotted against aging time.

There is a great difference in particle size between the cases with either a higher or a lower addition of urea. In lower urea content cases, e.g., 0.5 and $1 \mathrm{~mol} / \mathrm{L}$ of urea, the average particle size was less than $100 \mathrm{~nm}$ on aging for $9 \mathrm{~h}$. But when urea concentrations of 2 and $3 \mathrm{~mol} / \mathrm{L}$ were used, the measured size of the particles reached about $200 \mathrm{~nm}$ on aging for only $1 \mathrm{~h}$, and rapidly grew to $\geq 1000 \mathrm{~nm}$ in $6 \mathrm{~h}$. The ICP study, the ICP result of this process is shown in Fig. 3(b). A result similar to process A can be obtained; as the In ion in solution decreased to a level of $30 \mathrm{ppm}$, the $\mathrm{pH}$ value increased dramatically (Table I).

$\mathrm{B}$-series samples were dried at $105^{\circ} \mathrm{C}$ for $1 \mathrm{~h}$ and then observed by SEM. Only the case of B-4 is shown in Fig. 5. Sticklike precipitates could be observed in SEM micrographs (Figs. 5 (a) and (b)) on aging for $12 \mathrm{~h}$ or less. But on aging for a longer time, e.g., $16 \mathrm{~h}$, submicron cubic particles began to form and grew to a larger size on aging for $23 \mathrm{~h}$. The quantity or size of the cubic particle did increase with the aging time, as shown in Figs. 5(c) and (d).

The TEM image and diffraction pattern of stick-like particles in the B-4 case (aging for $12 \mathrm{~h}$ at $65^{\circ} \mathrm{C}$ ) are shown in Fig. 6. The detailed surface morphology and the surface condition of the stick-like particles can be observed clearly. The stick-like particles seem to consist of very thin rods having a diameter of about

Table I. Formulations and Experimental Conditions in this Study

\begin{tabular}{lccc}
\hline & \multicolumn{2}{c}{ Concentration $(\mathrm{mol} / \mathrm{L})$} & \\
\cline { 2 - 3 } Sample & $\mathrm{In}^{3+}$ & Urea & \\
\hline Process & $t_{0}(\mathrm{~min})$ \\
A-1 & 0.02 & 0 & \\
A-2 & 0.02 & 0.5 & 120 \\
A-3 & 0.02 & 1 & 55 \\
A-4 & 0.02 & 2 & 33 \\
A-5 & 0.02 & 3 & 28 \\
\hline Process B: aging & at $85^{\circ} \mathrm{C}$ & \\
B-1 & $65^{\circ} \mathrm{C}$ & & 0 \\
B-2 & 0.02 & & 0.5 \\
B-3 & 0.02 & & 1 \\
B-4 & 0.02 & & 3 \\
B-5 & 0.02 & & \\
\hline
\end{tabular}



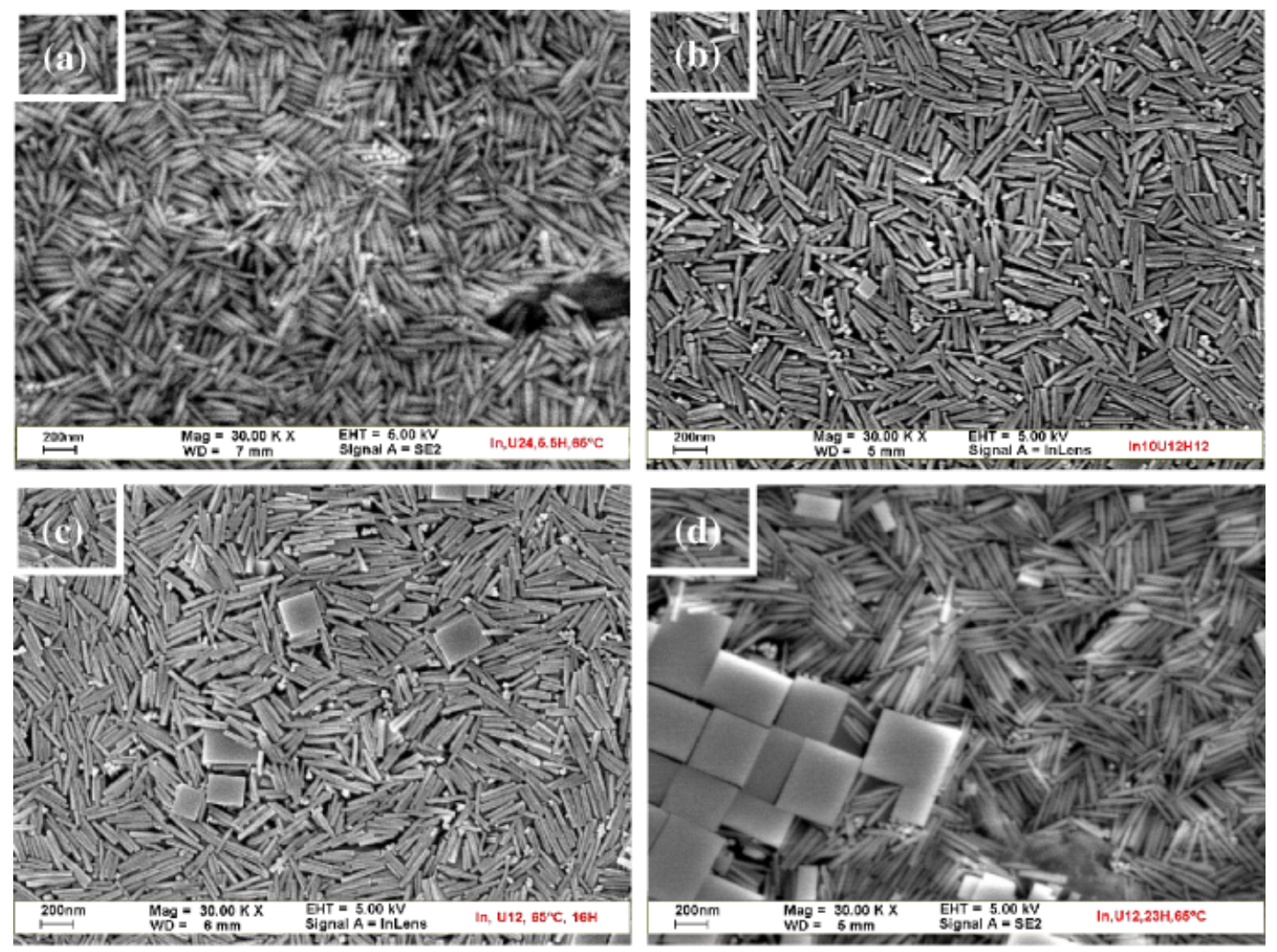

Fig. 5. Scanning electron microscope micrographs of B-4 sample aged for (a) $5 \mathrm{~h}$, (b) $12 \mathrm{~h}$, (c) $16 \mathrm{~h}$, and (d) $23 \mathrm{~h}$. Note that the fine cube-shaped particles grew after aging for $12 \mathrm{~h}$

6-10 nm. A similar structure can be seen for process A as well. The diffraction pattern in Fig. 6(b) reveals that the cubic-shaped particle is a cubic (BCC) structure of an $\mathrm{In}(\mathrm{OH})_{3}$ phase (JCPDF

(a)

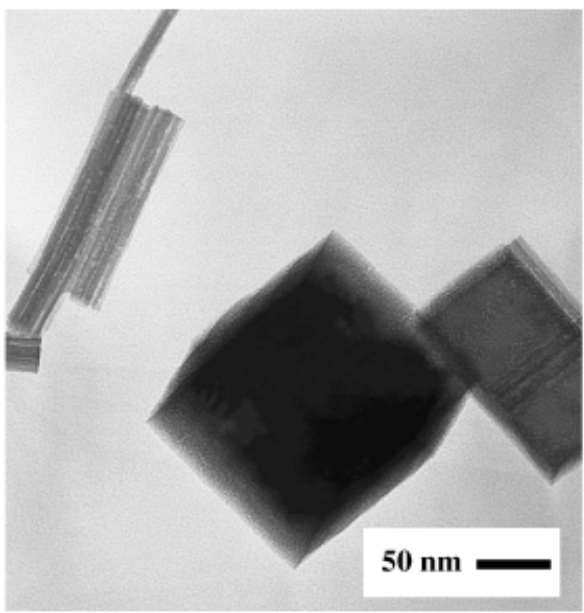

(b)
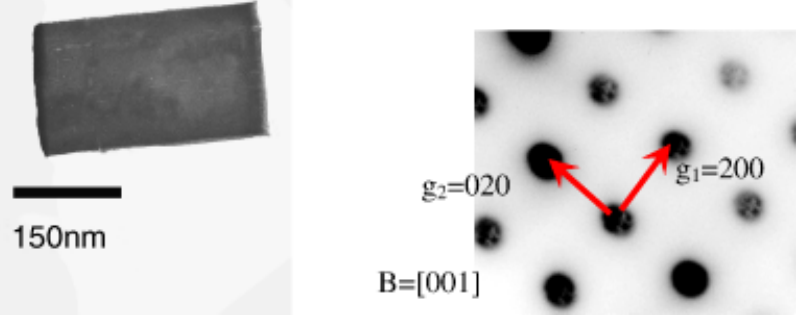

Fig. 6. (a) Transmission electron microscope BF micrograph and (b) diffraction pattern of a cubic particle with a zone axis [001]. The sample was obtained on aging for $23 \mathrm{~h}$ at $65^{\circ} \mathrm{C}$ with $2 \mathrm{~mol} / \mathrm{L}$ urea addition.
\# 16-161). The stick-like particles are poorly crystalline and become amorphous on exposure to a $100 \mathrm{keV}$ electron beam for a few minutes. A similar situation can be seen in the oval-like particle in process $A$.

The XRD results of the precipitate of the B-4 case with different aging periods are shown in Fig. 7. Note that the diffraction intensity in Fig. 7 is shown using a log scale. Two major peaks for the case of $12 \mathrm{~h}$ aging can be identified, i.e. (200) and

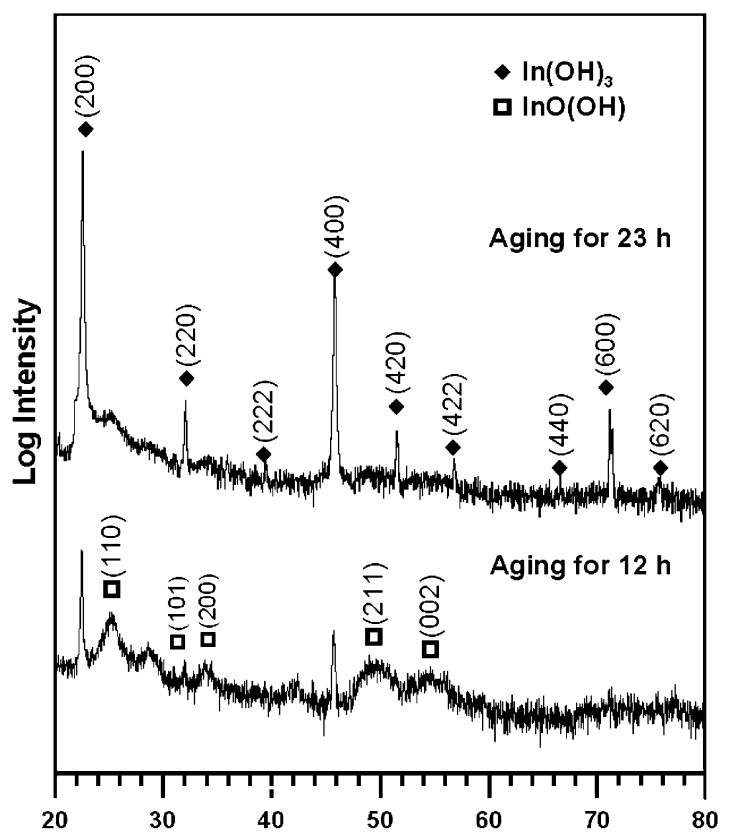

Fig. 7. X-ray diffractometer results of the precipitates of B-4 samples aged for 12 or $23 \mathrm{~h}$. The precipitates were dried at $105^{\circ} \mathrm{C}$ for $1 \mathrm{~h}$ before the test. 
(400) of the $\operatorname{In}(\mathrm{OH})_{3}$ phase. In addition, a minor $\operatorname{InO}(\mathrm{OH})$ phase can be identified. Compared with the diffraction information of $\operatorname{In}(\mathrm{OH})_{3}$ in JCPDF \# 16-161, the preferred orientation is apparently $\{200\}$. From the TEM diffraction pattern result, the cubic particles of $\operatorname{In}(\mathrm{OH})_{3}$ phase contributed to the major diffraction intensity in the spectrum. At the same time, the poor crystallinity of the $\mathrm{InO}(\mathrm{OH})$ phase provided the main diffraction intensity and induced boarder peaks as shown in the spectrum.

The TGA test result (not shown in this paper) of the B-4 sample aged for $23 \mathrm{~h}$ at a heating rate of $2^{\circ} \mathrm{C} / \mathrm{min}$ revealed that the main mass loss occurred at about $200^{\circ} \mathrm{C}$, indicating a dehydration reaction of the In precipitate at about $200^{\circ} \mathrm{C}$. In order to assure that a reaction occurred at this temperature, the precipitate was calcined at different temperatures and examined by XRD. After calcination at different temperatures for $1 \mathrm{~h}$ at a heating rate of $10^{\circ} \mathrm{C} / \mathrm{min}$, the XRD results revealed that on calcination at $200^{\circ} \mathrm{C}$, the powder sample still displayed the $\operatorname{In}(\mathrm{OH})_{3}$ phase, but disappeared and converted into an $\operatorname{In}_{2} \mathrm{O}_{3}$ phase at $300^{\circ} \mathrm{C}$ or a higher temperature. The XRD results of the samples treated at high temperatures show that the main weight loss occurred because of the decomposition of the $\operatorname{InO}(\mathrm{OH})$ and $\mathrm{In}(\mathrm{OH})_{3}$ phases into the $\mathrm{In}_{2} \mathrm{O}_{3}$ phase. However, a TGA test could not distinguish the exact temperature region between the dehydration of $\operatorname{InO}(\mathrm{OH})$ and $\operatorname{In}(\mathrm{OH})_{3}$ phases. This is because the dehydration temperature of both phases is approximately $200^{\circ} \mathrm{C}$ and almost overlaps.

After high-temperature calcinations of the precipitate, the particles almost retained their original morphology. In the case of the treatment at $900^{\circ} \mathrm{C}$, the particles still retained their shape, but nano-domains appeared on the surface. The domain boundaries could be observed on the surface of the cubic particles. Based on the results, monodispersive $\mathrm{In}_{2} \mathrm{O}_{3}$ particles can be obtained by heating at a temperature higher than $300^{\circ} \mathrm{C}$ for $1 \mathrm{~h}$.

It appeared that the $\mathrm{InO}(\mathrm{OH})$ phase was generated in the solution first. With increasing aging time the cubic $\operatorname{In}(\mathrm{OH})_{3}$ phase began to form. This change from mono-hydrate $\mathrm{InO}(\mathrm{OH})$ to the tri-hydrate phase is not common for an ordinary hydrothermal process. This may be becuase of the high concentration of urea addition. The decomposition of urea provides enough $(\mathrm{OH})^{-}$in the solution, and cubic particles would be formed by a particle-ripping phenomenon.

\section{Discussion}

\section{(1) Thermal-Activated Growth}

After completion of best fitting of the curves of ICP-OES tests as shown in Figs. 3(a) and (b), a linear relationship was observed between the concentration of the residual In ions and the aging time of the solution, in which the concentration of In was higher than the lowest level e.g., 3 ppm. The slopes of all the cases can be considered as the reaction rates of the precipitation.

The rate law for a zero-order reaction is ${ }^{16}$

$$
R=-\frac{\mathrm{d}[C]}{\mathrm{d} t}=k[C]^{0}=k
$$

where $k$ is the reaction rate $(\mathrm{ppm} / \mathrm{min}), R$ is the reaction rate, and $[C]$ is the concentration of $\mathrm{In}^{3+}$ in solution. The reaction rate $(R)$ is constant and independent of the concentration $[C]$ of the reacting substance. To calculate the kinetic behavior of the reaction, Eq. (1) is considered as a differential form, and integrating over a time period. Assuming that the concentration of $\mathrm{In}^{3+}$ at $t_{1}=0$ is $[C]_{0}$, and $t_{2}$ is $[C]_{t}$,

$$
\mathrm{d}[C]=-k \mathrm{~d} t
$$

where $t$ is the aging time (min). Equation (3) can be rewritten as

$$
[C]_{t}=[C]_{0}-k t
$$

A plot of $[C]$ versus time would yield a straight line with an intercept $[C]_{0}$ and a slope $k$. In the case of no urea addition the In ion was hydrolyzed and there was a decrease in the $\mathrm{pH}$ value of the solution:

$$
\mathrm{In}^{3+}+3 \mathrm{H}_{2} \mathrm{O} \rightarrow \operatorname{In}(\mathrm{OH})_{3}+3 \mathrm{H}^{+}
$$

In the case of urea addition, the In ion would react with $\mathrm{OH}^{-}$ which was supplied by the decomposition of urea:

$$
\mathrm{In}^{3+}+3(\mathrm{OH})^{-} \rightarrow \operatorname{In}(\mathrm{OH})_{3}
$$

The urea decomposition associated with the precipitation is

$$
\frac{3}{2}\left(\mathrm{NH}_{2}\right)_{2} \mathrm{CO}+\frac{9}{2} \mathrm{H}_{2} \mathrm{O} \rightarrow \frac{3}{2} \mathrm{CO}_{2}+3 \mathrm{NH}_{4}^{+}+3 \mathrm{OH}^{-}
$$

The relationship of urea decomposition with the precipitation of $\mathrm{In}(\mathrm{OH})_{3}$ can be shown by combining Eqs. (6) and (7).

$$
\begin{aligned}
& \mathrm{In}^{3+}+\frac{3}{2}\left(\mathrm{NH}_{2}\right)_{2} \mathrm{CO}+\frac{9}{2} \mathrm{H}_{2} \mathrm{O} \\
& \quad \rightarrow \operatorname{In}(\mathrm{OH})_{(p)}+\frac{3}{2} \mathrm{CO}_{2(g)}+3 \mathrm{NH}_{4}^{+}
\end{aligned}
$$

In the temperature range of $65^{\circ}-85^{\circ} \mathrm{C}$, the In ions would hydrolyze to form an In precipitate at a constant reaction rate, and possess the characteristics of a zero-order reaction. However, the reaction rate increased with increasing urea addition. In other words, the decomposition of urea controls the hydrolysis rate of $\mathrm{In}^{3+}$.

The ICP-OES results (Fig. 3) provided the evidence that the particle size in the case of higher urea additions did not increase after aging for more than $30 \mathrm{~min}$ (Fig. 2). Consequently, the $\mathrm{pH}$ value also remained constant.

The slopes of the reaction rates versus urea additions are defined as the rate constant $k$. The values of the reaction rate constant of processes A and B were 32.38 and 2.88, respectively. The dissimilarity between these two processes is because of the different decomposition rates of urea at $65^{\circ}$ or $85^{\circ} \mathrm{C}$. Shaw and Bordeaux ${ }^{17}$ reported the decomposition of urea in aqueous media at elevated temperatures. Their rate constant reported in the literature versus the processing temperature were plotted in Fig. 8 .

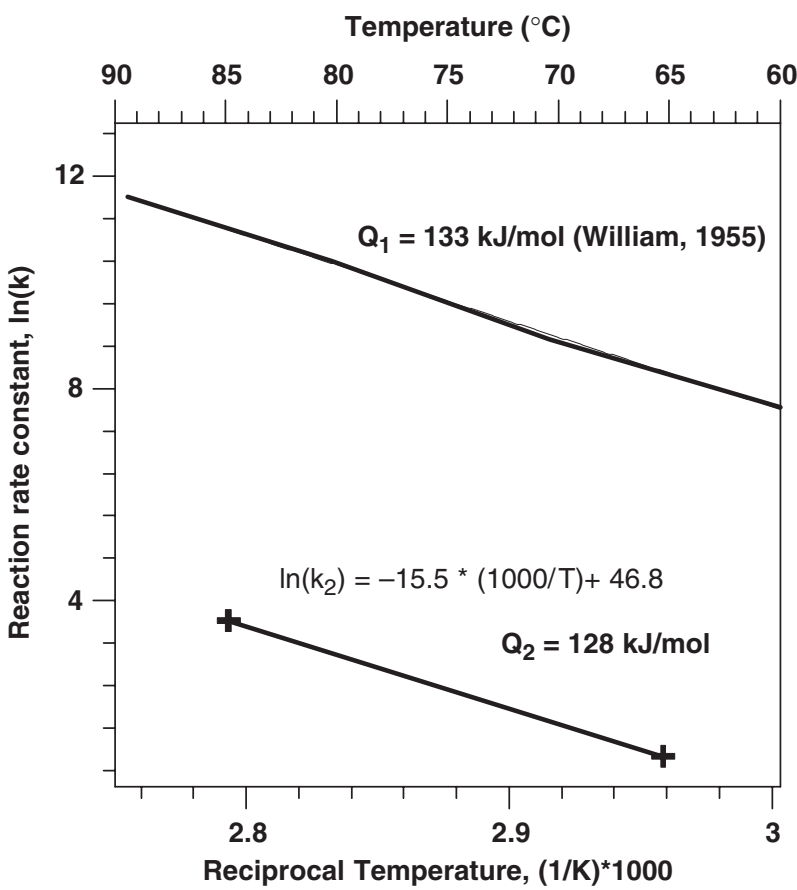

Fig. 8. Arrhenius plot of the rate constant versus the reciprocal Kelvin temperature. The activation energy $\left(Q_{1}\right)$ for the decomposition of urea reported by Shaw and Bordeaux ${ }^{17}$ was about $133 \mathrm{~kJ} / \mathrm{mol}$. The activation energy $\left(Q_{2}\right)$ for the precipitation of $\operatorname{In}(\mathrm{OH})_{3}$ is about $128 \mathrm{~kJ} / \mathrm{mol}$. 
The activation energy of the hydration reaction in Eq. (6) can be considered as the amount of energy that must be supplied in order to overcome an energy barrier for the reaction. The rate constant $k(T)$ varied as a function of the reciprocal absolute temperature. That is,

$$
k(T)=k_{0} \exp \left(-Q / R_{\text {gas }} T\right)
$$

where $k_{0}$ is the frequency factor or the pre-exponential factor, and $R_{\text {gas }}$ is the gas constant $\left(\mathrm{J} \cdot(\mathrm{mol} \cdot \mathrm{K})^{-1}\right), T$ is in absolute or Kelvin units.

An Arrhenius plot of the rate constant of processes A and B is shown in Fig. 8. The activation energy for the precipitation of In $\left(Q_{2}\right)$ was about $128 \mathrm{~kJ} / \mathrm{mol}$ and that for the decomposition of urea in aqueous media $\left(Q_{1}\right)$ reported by Shaw and Bordeaux ${ }^{17}$ was about $133 \mathrm{~kJ} / \mathrm{mol}$. The two $Q$ values are almost equal, implying that the control mechanism of the two reactions is the decomposition of urea in the aqueous solution.

\section{(2) Grain Growth Kinetics}

At a lower temperature of $65^{\circ} \mathrm{C}$, uniform elongated particles would form and grow into longer and wider stick-like particles. With increasing aging time, some stick-like particles could grow to cubic ones as shown in Fig. 5. At a higher aging temperature, the smaller precipitates became larger and longer with stick-like features but wider than at $65^{\circ} \mathrm{C}$, at a short time. The precipitation phenomenon then occurred at the waistline of the existing particles. The growth rate of the particle along the long axis was faster than the direction normal to the major axis. The changes in the length and the width of the particle by process A, with the aging time are plotted in Fig. 2. In all cases in process $A$, the differences in length were larger in terms of width before the residual In ions in solution reacted to a limiting value. This is the reason why, with particles growth, the ladder-like contour feature on the surface of the particles can be observed by SEM and TEM at a higher magnification because of different growth rates in two different directions.

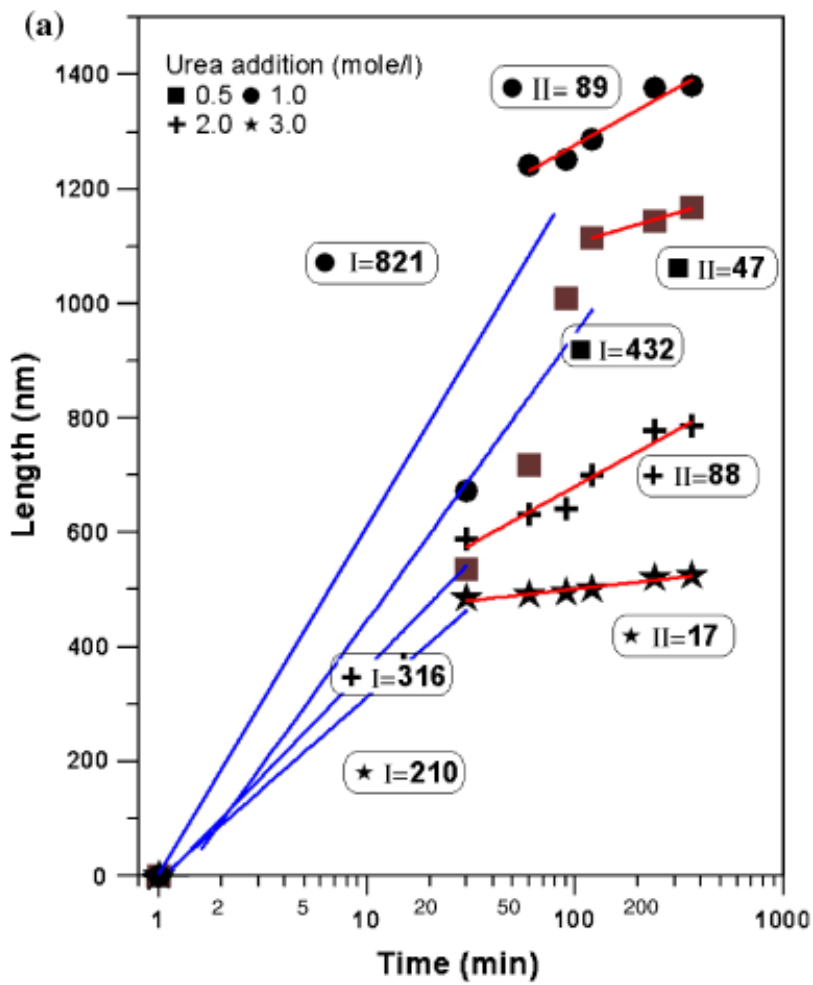

In process $\mathrm{A}$, the reaction at $85^{\circ} \mathrm{C}$ with different concentrations of urea addition, the growth behavior of the particles, and both the length and the width can be divided into two stages. The dividing line between these two stages is relative to the consumption of the concentration of $\mathrm{In}^{3+}$. Once the concentration of $\operatorname{In}^{3+}$ decreased to a limit as described above, the growth behavior would change from the first stage to the second stage. But among these two stages, the particle sizes, for length and width, exhibited a natural logarithmic relationship with respect to the reaction time, as shown in Figs. 9(a) and (b). The function of the particle size with respect to the reaction time can be written as follows ${ }^{16}$ :

$$
y=m_{i} \ln t+n
$$

where $y$ is the particle size (length or width), $m_{i}$ is the coefficient of the growth constant with $i \mathrm{~mol} / \mathrm{L}$ of urea addition, $t$ is the reaction time, and $n$ is an experimental constant.

During the first stage, the growth rate of the length for each case at any time is $m_{i} / t$, and $m_{i}=432,821,316$, and 210 for $i=0.5,1.0,2.0$, and 3.0 , respectively. At the same time, $m_{i}=113,166,95$, and 115 for the growth rate of the width. It can be found that irrespective of the length or width, $m_{l}$ always shows the largest value during the first growth stage.

During the second stage of growth, the function of the particle size with respect to the reaction time can also be represented as in Eq. (10). For the growth rate of length, $m_{i}=47,89,88$, and 17 , at the same time, for the growth rate of width, $m_{i}=19,10$, 26 , and 10 .

Besides $m_{3}$, the ratio of $\left[m_{i}\right]_{\text {first }}$ to $\left[m_{i}\right]_{\text {second }}$ is approximately 10 , which means that when the concentration of $\mathrm{In}^{3+}$ in the solution is as low as the critical limit, the growth rate constant would decrease ten times. The similar condition can be observed in the cases of width.

In process $\mathrm{B}$, the particle size (measured by a Particle Sizer) still exhibited a natural logarithmic relationship with respect to the reaction time, but only one stage could be observed. This is

Fig. 9. (a) Particle size (length) aging at $85^{\circ} \mathrm{C}$ plotted against logarithmic aging period with the addition of different urea concentrations. The rates in the various stages and the urea additions can be noted beside the data-fitting lines. (b) Particle size (width) aging at $85^{\circ} \mathrm{C}$ plotted against logarithmic aging period with the addition of different urea concentrations. The rates in various stages and urea additions can be noted beside the data-fitting lines.

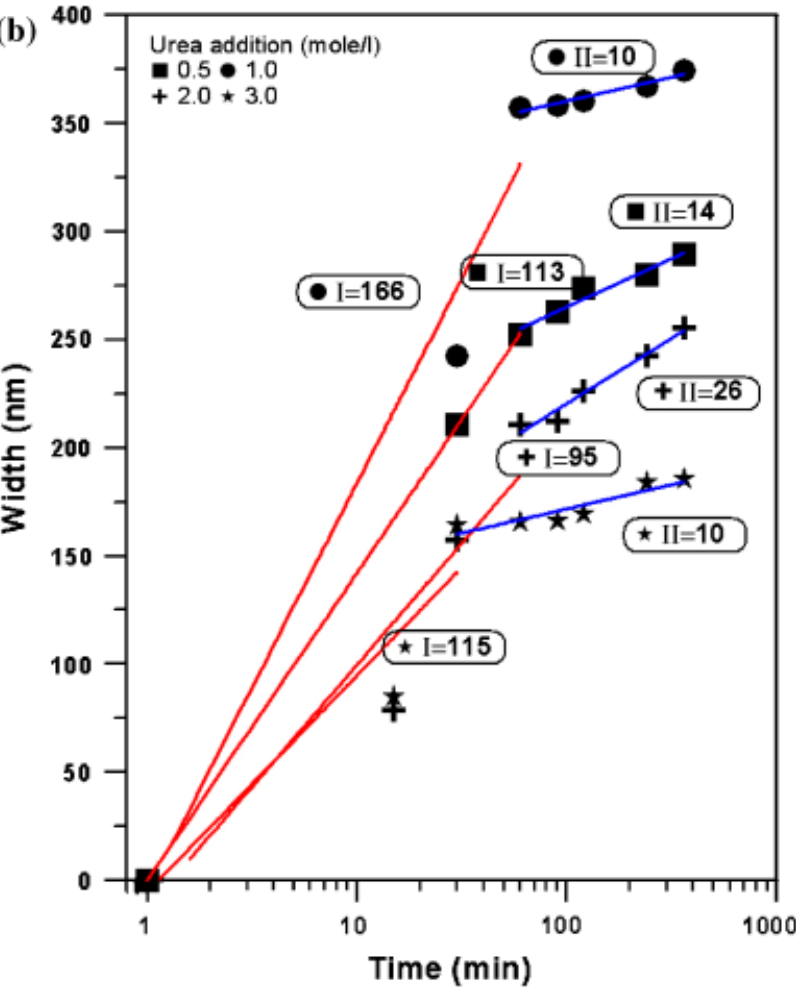




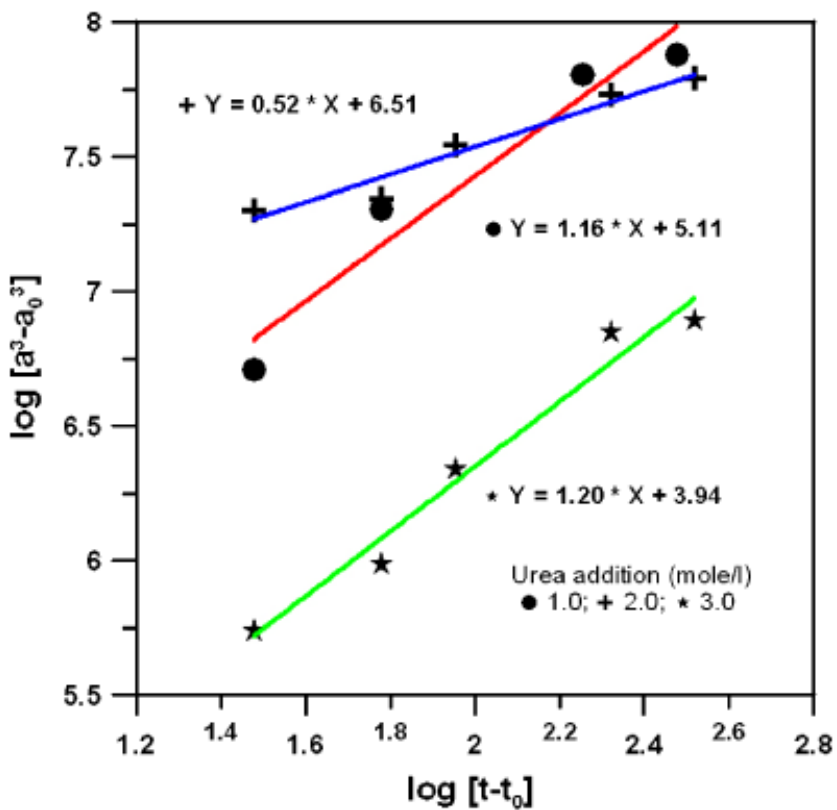

Fig. 10. Growth of the particle (at $85^{\circ} \mathrm{C}$ ) during the second stage on additions of various urea concentrations can be noted beside the datafitting lines, where $a$ is the geometric mean of length and width, $a_{0}$ is the geometric mean of length and width at the initial point of the second stage. At this point, the reaction time was set as $t_{0}$.

because the residual $\mathrm{In}^{3+}$ in this process becomes as low as the critical limit.

At a reaction temperature of $85^{\circ} \mathrm{C}$, the growth of the particle during the second stage at various concentrations of urea addition can be noted beside the data-fitting lines as shown in Fig. 10, where $a$ is a geometric mean of the length and width, $a_{0}$ is the geometric mean of length and width at the initial point of the second stage which can be seen in Fig. 9. At this point, the reaction time is set as $t_{0}$. When 1.0 and $3.0 \mathrm{~mol}$ of urea are added the slopes of the fitting line are approximated to one, which means that the reaction is diffusion controlled in the second stage.

\section{Conclusions}

Oval-, stick-, and cubic-shaped particles were synthesized through the processes of solution aging at $65^{\circ}$ and $85^{\circ} \mathrm{C}$. The particles were assembled from thin rods of about $30 \mathrm{~nm}$ or less in diameters. The consumption rates of In ion revealed the precipitation kinetics of the In-hydrate particles to be zero-order reactions with time. Two types of precipitate particles were formed. On aging at $65^{\circ} \mathrm{C}$, poor crystalline, stick-like $\mathrm{InO}(\mathrm{OH})$ particles precipitated, and single crystalline cubic-shaped $\operatorname{In}(\mathrm{OH})_{3}$ particles could be generated because of the ripening effect owing to the surface energy and the strong basic condition. The amorphotization phenomenon of the green or $300^{\circ} \mathrm{C}$ calcined stick-like particles was induced by a TEM electron beam. The preferred orientation of the $\{200\}$ phases of $\operatorname{In}(\mathrm{OH})_{3}$ was identified. The shape of these particles can be maintained even on heating up to $900^{\circ} \mathrm{C}$. The reaction constants of $\mathrm{In}^{3+}$ aged at $65^{\circ}$ and $85^{\circ} \mathrm{C}$ were 2.9 and 32.4, respectively. After calculation by the Arrhenius equation, the activation energy of $\mathrm{In}^{3+}$ precipitation was $128 \mathrm{~kJ} / \mathrm{mol}$, and controlled by the decomposition of urea.

\section{References}

${ }^{1}$ H. Zhou, W. Cai, and L. Zhang, "Photoluminescence of Indium-Oxide Nanoparticles Dispersed Within Pores of Mesoporous Silica," Appl. Phys. Lett., 75 [4], 495-7 (1999).

${ }^{2}$ Y. Li, Y. Bando, and D. Golberg, "Single-Crystalline $\operatorname{In}_{2} \mathrm{O}_{3}$ Nanotubes Filled with In," Adv. Mater., 15 [7-8], 581-5 (2003).

${ }^{3}$ K. Soulantica, L. Erades, M. Sauvan, F. Senocq, and A. Maisonnat, "Synthesis of Indium Oxide Nanoparticles from Indium Cyclopentadienyl Precursor and Their Application for Gas Sensing," Adv. Funct. Mater., 13 [7], 1330-3 (2001).

${ }^{4}$ S. Sato, "Photocatalytic Activities of Indium Oxide Powder Prepared from Indium Hydroxide," J. Photochem. Photobio. A: Chem., 45, 361-7 (1988).

${ }^{5}$ L. Hong and E. Ruckenstein, "Conductive Coating Films Based on Low Density $\mathrm{In}_{2} \mathrm{O}_{3}$ Powders and Polymer Latexes," J. Appl. Polym. Sci., 61, 901-9 (1996).

${ }^{6}$ C. Liang, G. Meng, and Y. Lei, "Catalytic Growth of Semiconducting $\operatorname{In}_{2} \mathrm{O}_{3}$ Nanofibers," Adv. Mater., 13 [17], 1330-3 (2001).

${ }^{7}$ F. Boschini, B. Robertz, A. Rulmont, and R. Cloots, "Preparation of Nanosized Barium Zirconate Powder by Thermal Decomposition of Urea in an Aqueous Solution Containing Barium and Zirconium and by Calcination of the Precipitation," J. Eur. Ceram. Soc., 23, 3035-42 (2003).

${ }^{8}$ L. Wang, I. Sondi, and E. Matijevic, "Preparation of Uniform Needle-Like Aragonite Particles by Homogeneous Precipitation," J. Colloid Interface Sci., 218, 545-53 (1999)

${ }^{9}$ K. C. Song and Y. Kang, "Preparation of High Surface Area Tin Oxide Powders by a Homogeneous Precipitation of Zinc Sulfide from Acidic Zinc Salt Solution," Colloids Surfaces A: Physicochem. Eng. Aspects, 151, 505-12 (1999).

${ }^{10}$ A. Eshuis, G. R. A. van Elderen, and C. A. J. Koning, "A Descriptive Model for the Homogeneous Precipitation of Zinc Sulfide from Acidic Zinc Salt Solutions," Colloids Surfaces A: Physicochem. Eng. Aspects, 151, 505-12 (1999).

${ }^{11}$ J. Subrt, J. Bohacek, V. Stengl, T. Grygar, and P. Bezdicka, "Uniform Particles with a Large Surface Area Formed by Hydrolysis of $\mathrm{Fe}_{2}\left(\mathrm{SO}_{4}\right)_{3}$ with Urea," Mater. Res. Bull., 34 [6] 905-14 (1999).

${ }^{12}$ J. Li, T. Ikegami, Y. Wang, and T. Mori, " $10 \mathrm{Mol}^{\%} \mathrm{Gd}_{2} \mathrm{O}_{3}-$ Doped $\mathrm{CeO}_{2}$ Solid Solutions via Carbonate Coprecipitation: A Comparative Study," J. Am. Ceram. Soc., 86 [6] 915-21 (2003).

${ }^{13}$ Y. Wang, T. Mori, J. Li, and Y. Yajima, "Low-Temperature Fabrication and Electrical Property of $10 \mathrm{Mol} \% \mathrm{Sm}_{2} \mathrm{O}_{3}$-Doped $\mathrm{CeO}_{2}$ Ceramics," Sci. Tech. Adv. Mater., 4, 229-38 (2003).

${ }^{14}$ X. C. Jiang, C. H. Yan, Z. G. Sun, L. D. Wei, and C. S. Liao, "Hydrothermal Homogeneous Urea Precipitation of Hexagonal $\mathrm{YBO}_{3}: \mathrm{Eu}^{3+}$ Nanocrystals with Improved Luminescent Properties," J. Solid State Chem., 175, 245-51 (2003).

${ }^{15}$ S. Avivi, Y. Mastai, and A. Gedanken, "Sonohydrolysis of $\mathrm{In}^{3+}$ Ions: Formation of Needelike Particles of Indium Hydroxide," Chem. Mater., 12, 1229-33 (2000)

${ }^{16}$ J. I. Steinfeld, J. S. Francisco, and W. L. Hase, Chemical Kinetics and Dynamics, 2nd edition, Chapter 1, p. 6. Prentice-Hall Inc, Englewood Cliffs, NJ, 1999.

${ }^{17}$ W. H. R. Shaw and J. J. Bordeaux, "The Decomposition of Urea in Aqueous Media," J. Chem. Soc., 77, 4729 (1955) 